\title{
Effect of Collagen Denaturation on the Toughness of Bone
}

\author{
Xiaodu Wang, PhD*; Ruud A. Bank, PhD**; \\ Johan M. TeKoppele, PhD'; Gene B. Hubbard, DVM, MS'; \\ Kyriacos A. Athanasiou, PhD*; and C. Mauli Agrawal, PhD*
}

The purpose of this study was to explore the relationship between the integrity of collagen and biomechanical properties of bone. In this study, age (range, 5-26 years old) and gender related changes in cortical bone samples from 33 baboon femurs ( 15 males and 18 females) were examined. The percentage of denatured collagen was determined using a selective digestion technique. The fracture toughness, elastic modulus, yield and ultimate strength, and energy to fracture of bone were determined in three-point bending configurations. The porosity and weight fractions of the mineral and organic phase also were measured. A two-way analysis of variance showed that age dependent changes were reflected primarily in the amount of denatured collagen, fracture toughness, energy to

From the *Musculoskeletal Bioengineering Center, the University of Texas Health Science Center, San Antonio, TX: the **Division of Vascular and Connective Tissue Research, Organization for Applied Scientific Research (TNO), Leiden. The Netherlands; and the 'Department of Laboratory Animal Medicine, Southwest Foundation for Biomedical Research, San Antonio, TX.

Reprint requests to Xiaodu Wang. PhD, Orthopaedic Bioengineering, University of Texas Health Science Center at San Antonio, 7703 Floyd Curl Drive, San Antonio, TX 78284.

Received: May 7, 1998.

Revised: October 21, 1998; March 11, 1999; April 23, 1999.

Accepted: May 10, 1999. fracture, and elastic modulus, whereas gender had effects on the fracture toughness, elastic modulus, and porosity of bone. In addition, regression analyses indicated that the percentage of denatured collagen had an inverse correlation with the toughness of bone and a positive correlation with its elastic modulus, whereas mineral content had positive correlation with the strength and elastic modulus of bone. The results of this study suggest collagen influences the toughness of bone, whereas mineral content predominantly contributes to bone stiffness and strength.

Age related bone fractures are a major cause of morbidity and mortality among the elderly. ${ }^{10.11 .43}$ For instance, it has been reported that approximately $50 \%$ of patients with hip fractures become partially or totally dependent on assistance for their daily activities. ${ }^{26.37}$ Thus, it is of interest to understand the underlying mechanisms of age related changes in bone that contribute to such fractures and subsequently to predict and prevent these adverse changes.

Bone is a natural composite primarily comprising mineral (primarily hydroxyapatite crystals) and organic (90\% Type I collagen) phases. ${ }^{27}$ Thus, its biomechanical properties are dependent on the quality, spatial arrangements, and interaction of these components. 
Low bone mineral density has been considered to be a major cause of age related bone fractures, ${ }^{1,32,43}$ so it has been used commonly as a predictor of fracture risk. ${ }^{14,44}$ However, in recent years there has been growing awareness that low bone density is not the only reason for weakening of bone because a large overlap in bone density exists between healthy individuals and patients who sustain bone fractures. ${ }^{14.40 .44}$ For instance, Hui et al ${ }^{21}$ found that at the same level of bone density, the risk of bone fracture for older women (average, 75 years old) is approximately 70 per 1000 , whereas such a risk is only 10 per 1000 for younger individuals (average, 45 years old). In addition. it has been shown that disorders in bone Type I collagen molecules, such as those in osteogenesis imperfecta, can make bone extremely susceptible to fracture. ${ }^{13}$ It has been found that osteoporotic bone fractures are relatively rare in elderly Gambian women compared with their Caucasian counterparts, although low bone mass is common in the elderly for both ethnic groups. ${ }^{2}$ All of these clinical findings suggest that the mineral phase is not the only factor affecting biomechanical properties of bone; other parameters also may play an important role in determining the mechanical integrity of bone.

Previous laboratory studies have suggested that changes in collagen may correlate significantly with bone mechanical properties. The collagen matrix in bone has a highly hierarchical structure. The Type I collagen molecule is the basic building block of the matrix and is characterized by a triple helical structure of three amino acid chains. These molecules are crosslinked to form collagen fibrils, which aggregate into collagen fibers and finally into the collagen network. ${ }^{7.49}$ Thus, the integrity of collagen molecules and crosslinks is critical to the structural stability of the collagen network and consequently influences biomechanical properties of bone. For instance, defects in collagen molecules, such as collagen mutations seen in osteogenesis imperfecta, can lead to the increased bone fragility. ${ }^{22.23}$ Oxlund et al ${ }^{41,42}$ found that the concentration of collagen crosslinks decreases in aged and osteoporotic bone, and such a change is associated with the decreased mechanical strength of bone in rats. In addition, Danielsen et al ${ }^{19}$ reported the tensile strength of demineralized bone in rats decreases with age. Kovach et al, ${ }^{28.29}$ using a laser autofluorescence technique, showed that age dependent changes in the collagenous matrix of bone correlate significantly with bone fracture toughness. These findings also support the speculation that the collagen phase in bone may contribute to the retention of toughness in aging bone. ${ }^{38}$

Over the years, numerous techniques have been developed to detect changes in the collagen network of bone. For example, to directly determine the percentage of degraded collagen molecules (unwound and cleaved), a new technique was developed recently that uses a selective digestion procedure to distinguish between denatured and intact collagen molecules. ${ }^{6}$ To assess the structural stability of the collagen network, its thermostability has been measured frequently using calorimetry or collagen shrinkage. ${ }^{18.39}$ The morphologic properties of the collagen network in bone can be evaluated using transmission electron microscopic analysis to determine the spatial arrangement and geometry of collagen fibrils. ${ }^{8.51}$ In addition, mechanical tests of demineralized bone samples have been used to assess the structural strength of the collagen network. 19,25

The hypothesis of this study is that bone biomechanical properties correlate significantly with the extent of Type I collagen denaturation, and such changes in collagen contribute primarily to the reduced toughness of bone. To test this hypothesis in the current study, the biomechanical properties and the denaturation of collagen molecules of cortical bone samples from baboon femurs were determined as a function of age. The biomechanical properties of bone were determined in three-point bending tests in terms of elastic modulus, yield strength, ultimate strength, fracture toughness, and energy to fracture. The percentage of the denatured collagen in bone was determined using the unique selective 
digestion technique. ${ }^{6}$ Measurements of bone porosity and weight fractions of the mineral and organic phases also were performed. The correlations of collagen denaturation, porosity, and mineral content with bone mechanical properties were explored.

\section{MATERIALS AND METHODS}

Fresh femurs were obtained from 15 male and 18 female baboons (age range, 5-26 years; average age, 13.8 years) from the Southwest Foundation for Biomedical Research, San Antonio, Texas. All animals were screened carefully to avoid the influence of any diseases on bone samples. After harvest, the femurs were fresh frozen immediately at $-20^{\circ} \mathrm{C}$ until testing. In general, baboons reach skeletal maturity at approximately 6 years of age, ${ }^{5}$ and their life span usually is considered to be approximately 20 years. To cover the age groups of young adults, middle aged, and the elderly, these animals were divided into three age groups: 6 to 9 , 10 to 16 , and older than 16 years of age, respectively. Each of the age groups included five males and six females. From each femur, a 40-mm section of middiaphysis was excised, and two 4-mm thick slices were cut from the proximal and distal ends of this section for the quantitative analysis of collagen denaturation. The measurements from the distal and proximal slices were averaged for each animal. From the lateral aspect of the remaining excised diaphysis, two bone coupons ( $30 \times 4 \times 2 \mathrm{~mm}$ ) were obtained longitudinally using a diamond saw and a bench top milling machine. Haversian bone was the dominant microstructure of these bone samples. One of the two coupons was used for a fracture toughness test to assess the transverse fracture toughness of bone. The other was used for a threepoint bending test to determine the elastic modulus, yield strength, ultimate strength, and energy absorbed until failure.

The fracture toughness test was performed in a three-point bending configuration following the appropriate standard recommended by the American Society for Testing and Materials. ${ }^{4}$ A precrack was introduced in the middle of the bone specimen using a circular saw and a sharp razor blade. Test specimens were supported in a custom designed fixture with a support span of $16 \mathrm{~mm}$. A compression load was applied in the middle of the specimens at a loading rate of $5 \mathrm{~mm}$ per minute in an Instron material testing machine (model 1011 . In- stron Corp, Canton, MA) until failure. The curve of load versus displacement was recorded using a computer controlled data acquisition system, and fracture toughness values were calculated following the standard. ${ }^{4}$ Because the precrack created in the specimens propagates in a direction perpendicular to the longitudinal axis of the diaphysis, the property actually measured in this test was the transverse fracture toughness. For the three-point bending test, experimental procedures and calculation of the elastic modulus and strength followed the standard D790-86 published by the American Society for Testing and Materials. ${ }^{3}$ From the recorded curve of load versus displacement, the work to fracture was calculated as the area under the curve. Because of the limitation of bone stock, specimen sizes in the fracture toughness and threepoint bending tests were smaller than those recommended in the standards. However, a relative comparison between these specimens should be valid because all of them had the same shape and size and were tested under the same condition.

A selective digestion technique was used to determine the amount of denatured collagen molecules (as percentage of the total amount of collagen). As shown in Figure 1, bone samples first were demineralized in a buffered $(\mathrm{pH} 7.4) 0.5$ mol ethylenediaminetetraacetic acid to remove all minerals. The demineralized bone samples then were digested at $37^{\circ} \mathrm{C}$ in $\alpha$-chymotrypsin solution. Because $\alpha$-chymotrypsin selectively dissolves degraded collagen. the degraded and intact collagen can be separated by removing the supematant (containing the degraded collagen) from the remaining insoluble matrix (containing the intact collagen). Thereafter the amounts of collagen in the supernatant (degraded collagen) and the residue (intact collagen) were determined by measuring the collagen specific amino acid hydroxyproline in both fractions. Finally, the percentage of denatured collagen was calculated by dividing the hydroxyproline concentration in supematant by the sum of hydroxyproline concentration in supernatant and remaining matrix. A detailed description of this technique can be found elsewhere. ${ }^{6}$

To obtain the weight fractions of mineral and organic phases of bone, half of each specimen used in the fracture toughness test was weighed in air under wet and dried conditions to acquire its wet and dry weights. To dehydrate the bone, the samples were placed in a vacuum oven ovemight at a temperature of $70^{\circ} \mathrm{C}$. The bone samples were heated at 


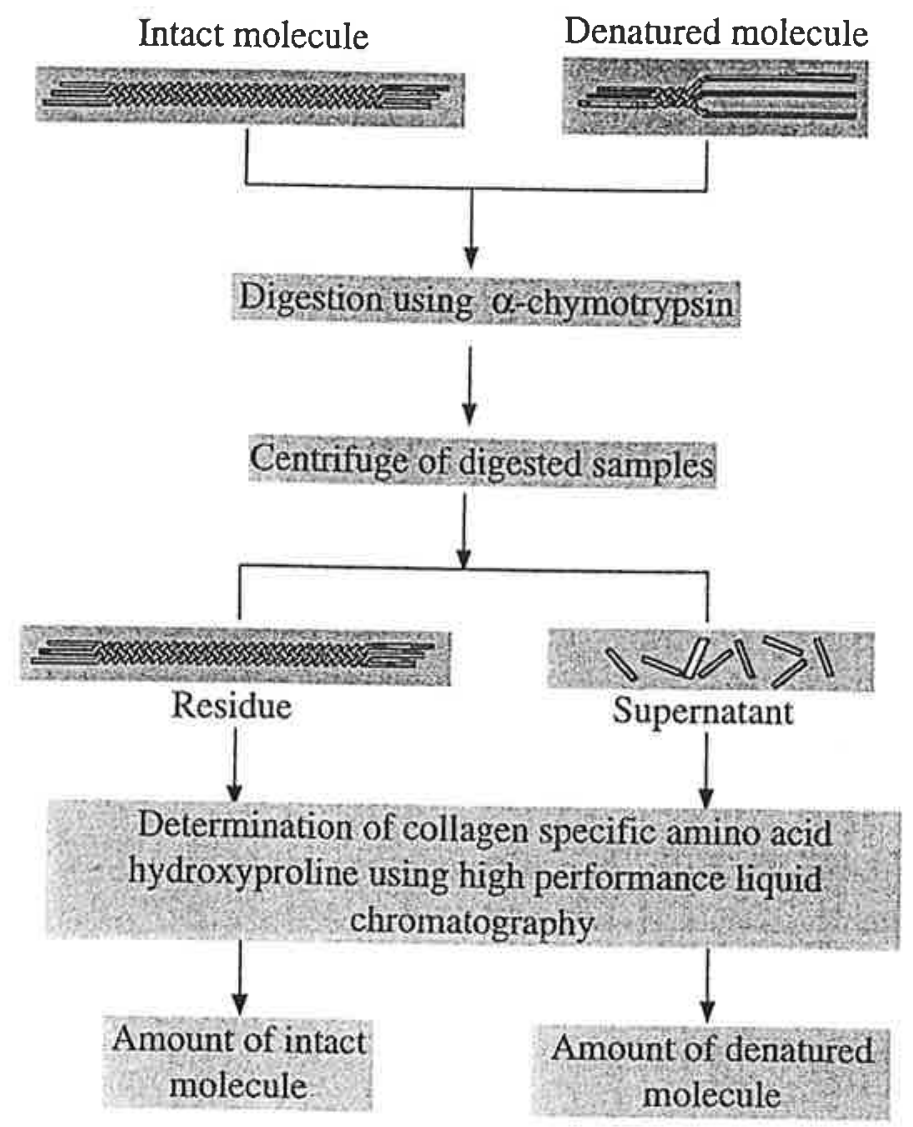
Fig 1. Schematic representation of the selective digestion technique used in this study to quantify the
amount of denatured collagen molecules.

$800^{\circ} \mathrm{C}$ in a crucible in a high temperature furnace for 3 hours. ${ }^{46}$ The weight of ash residue was considered to be the weight of the bone mineral, and the discrepancy between the dry weight and ash weight was deemed to be the weight of the organic phase. The weight fractions of mineral and organic phases were calculated by dividing the weight of ash residue and weight of organic phase by wet weight of bone, respectively.

The measurements of porosity were performed on the other half of the specimen used for the fracture toughness test. The cross section adjacent to the fracture site was embedded in a plastic resin and polished following standard procedures for engineering materials. An image of the cross section was digitized into a computer via a light microscope. An image processing and computational code written in a macroprogramming language
(NIH Image, National Institute of Health, Bethesda, MD) was used to calculate the ratio of the area of cavities (Haversian and vascular canals) to the whole cross sectional area. This ratio was defined as the porosity of bone.

All experimental data were compiled as mean and standard deviation (mean \pm standard deviation). A two-way analysis of variance (ANOVA) was performed to examine the effects of age and gender on all measured parameters in the baboon model, and multiple comparisons (Fisher's protected least significant difference) were made to detect significant differences between the groups. In addition, multiple regression analyses were used to explore the correlations of bone biomechanical properties with mineral content, collagen denaturation, and porosity of bone. The Pearson product moment correlation coefficients were calculated to 

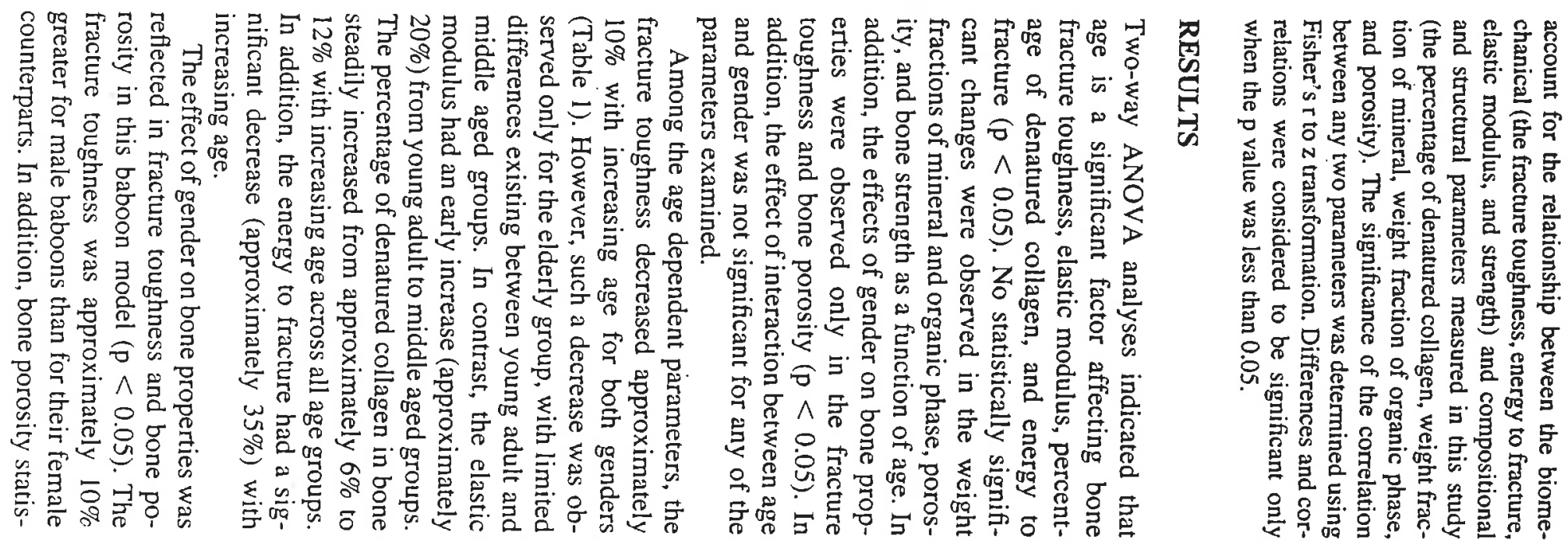

TABLE 1. Summary of Experimental Data and ANOVA Analyses

\begin{tabular}{|c|c|c|c|c|c|c|c|c|c|c|}
\hline $\begin{array}{l}\text { Age } \\
\text { (years) }\end{array}$ & Gender & $\begin{array}{l}W F_{m} \\
(\%)\end{array}$ & $\begin{array}{l}W F_{0} \\
(\%)\end{array}$ & $\begin{array}{c}\% D C \\
(\%)\end{array}$ & $\begin{array}{c}\mathrm{K}_{\mathrm{Ic}} \\
(\mathrm{MPa}[\mathrm{sr}] \mathrm{m})\end{array}$ & $\begin{array}{c}W_{f} \\
\text { (N.mm) }\end{array}$ & $\begin{array}{c}E \\
(\mathrm{GPa})\end{array}$ & $\begin{array}{c}\sigma_{y} \\
(\mathrm{MPa})\end{array}$ & $\begin{array}{c}\sigma_{8} \\
(\mathrm{MPa})\end{array}$ & $\begin{array}{l}\text { Po } \\
(\%)\end{array}$ \\
\hline \multirow[t]{2}{*}{$5-9$} & $M(n=5)$ & $60.3 \pm 1.8$ & $33.6 \pm 1.2$ & $5.7 \pm 1.3$ & $7.3 \pm 0.5$ & $181 \pm 46$ & $9.5 \pm 1.8$ & $473 \pm 61$ & $584 \pm 58$ & $2.5 \pm 0.8$ \\
\hline & $F(n=6)$ & $61.7 \pm 1.2$ & $33.7 \pm 0.4$ & $6.9 \pm 1.1$ & $6.7 \pm 0.7$ & $187 \pm 51$ & $9.2 \pm 1.3$ & $640 \pm 53$ & $640 \pm 53$ & $3.0 \pm 1.4$ \\
\hline \multirow[t]{2}{*}{$10-16$} & $M(n=5)$ & $62.7 \pm 1.0$ & $33.5 \pm 0.5$ & $9.5 \pm 1.4$ & $7.2 \pm 0.6$ & $176 \pm 28$ & $11.2 \pm 1.5$ & $527 \pm 46$ & $634 \pm 55$ & $1.7 \pm 0.5$ \\
\hline & $F(n=6)$ & $62.6 \pm 1.6$ & $32.7 \pm 0.4$ & $8.2 \pm 2.2$ & $6.3 \pm 0.4$ & $133 \pm 13$ & $12.8 \pm 1.5$ & $593 \pm 52$ & $593 \pm 52$ & $3.1 \pm 1.5$ \\
\hline \multirow[t]{2}{*}{$>16$} & $M(n=5)$ & $63.5 \pm 0.8$ & $32.8 \pm 0.6$ & $12.7 \pm 3.3$ & $6.5 \pm 0.5$ & $127 \pm 19$ & $12.0 \pm 1.3$ & $601 \pm 48$ & $601 \pm 48$ & $2.2 \pm 0.9$ \\
\hline & $F(n=6)$ & $619 \pm 1.3$ & $33.4 \pm 0.6$ & $10.5 \pm 2.7$ & $58 \pm 0.7$ & $115 \pm 34$ & $13.4 \pm 1.2$ & $580 \pm 57$ & $580 \pm 57$ & $4.7 \pm 3.8$ \\
\hline ANOVA & Age & 0.07 & 0.1 & $0.0001^{\star}$ & $0.0013^{*}$ & $0.004^{*}$ & $0.014^{\circ}$ & 0.93 & 0.93 & 0.41 \\
\hline \multirow[t]{2}{*}{$p$ values } & Gender & 0.60 & 0.84 & 0.08 & $0.0002^{=}$ & 029 & 0.09 & 0.88 & 0.59 & 0.03 \\
\hline & $A \times G$ & 0.06 & 007 & 0.06 & 031 & 0.39 & 0.99 & 0.34 & 0.17 & 0.43 \\
\hline
\end{tabular}


tically was greater for females than for age matched males. However, bone porosity was only a few percent for both genders.

Multiple regression analyses indicated the percentage of denatured collagen had a strong correlation with the fracture toughness, energy to fracture, and elastic modulus of bone, whereas the weight fraction of mineral content correlated primarily with bone strength and elastic modulus. However, the porosity and weight fraction of organic content appeared to have weak correlations with any of the biomechanical properties measured. It was observed that the rate of change in the fracture toughness as a function of the percentage of denatured collagen was remarkably different between genders, showing a sharper decrease for females compared with males (Fig 2). In contrast, only a weak correlation was observed between the percentage of denatured collagen and bone fracture toughness of males. However, changes in all parameters other than fracture toughness showed a similar trend for both genders. Thus, the data from both genders were combined for the regression analysis of the other parameters.

As shown in Figure 2, with an increase in the percentage of denatured collagen from $5 \%$ to $15 \%$, the energy to fracture decreased almost $40 \%$, whereas the fracture toughness decreased approximately $20 \%$ for females and less than $10 \%$ for males, respectively. This result suggests that bone becomes more susceptible to fracture when the amount of denatured collagen molecules increases in bone. In addition, strong correlation was found between the bone strength and the mineral content in bone. The yield and ultimate strength of bone increased with the weight fraction of mineral (Fig 3). The elastic modulus increased as mineral content and the amount of denatured collagen in bone increased (Fig 4).

Strong correlations were found between several of the biomechanical properties measured, as shown in Table 2. The fracture toughness had a positive correlation with the
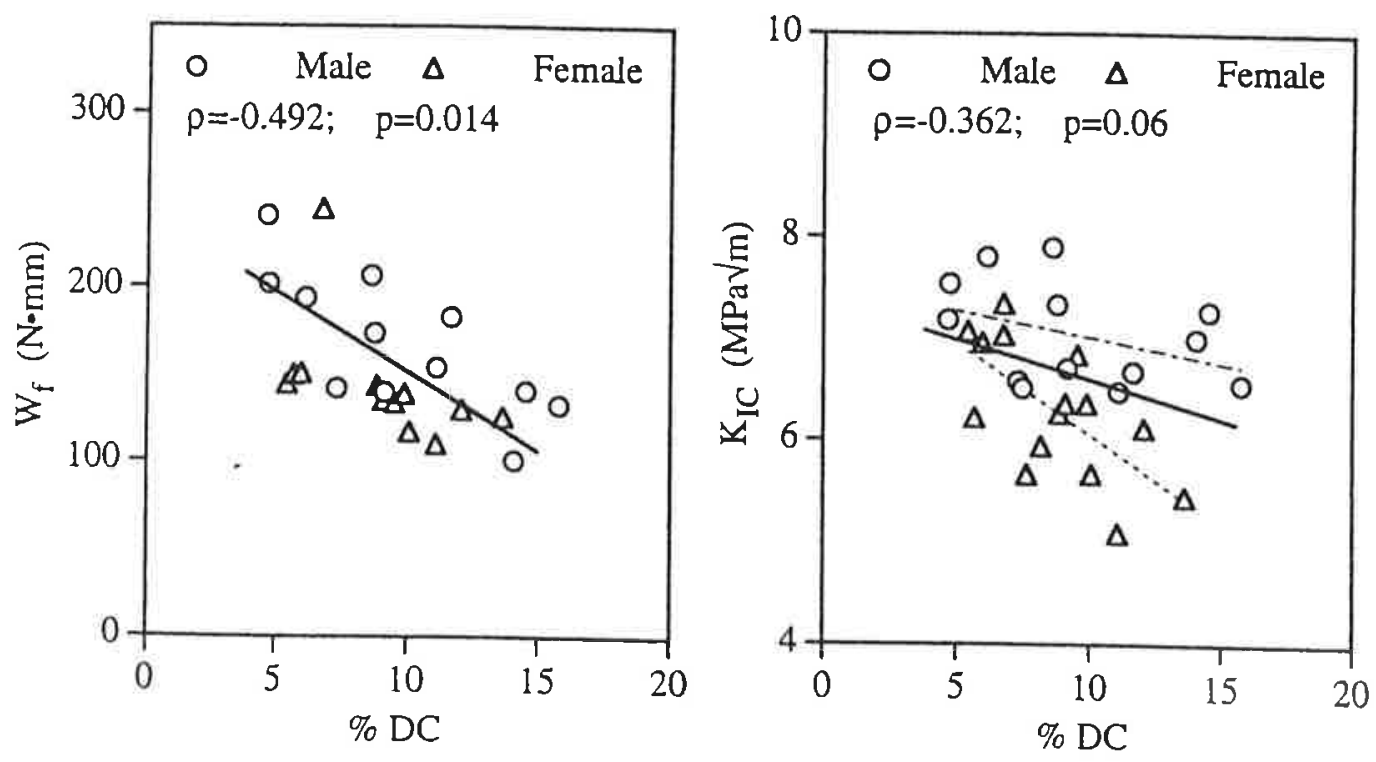

Fig 2. Regression of the fracture toughness $\left(K_{I C}\right)$ and energy to fracture $\left(W_{t}\right)$ with respect to the collagen denaturation $(\% D C)$ of bone for both genders, with the correlation coefficient $(\rho)$ and $p$ values being presented. Significant correlations were found between these parameters. Bone fracture toughness of female baboons showed a steeper decrease with collagen denaturation than did that of male
baboons. 
energy to fracture and a negative correlation with the elastic modulus but no statistically significant correlation with the strength of bone. The elastic modulus had a negative correlation with the energy to fracture and a positive correlation with yield strength, but not with the ultimate strength. In addition, the energy to fracture showed strong correlations with the ultimate strength of bone. The correlation between the yield and ultimate strength was statistically significant. Table 3 shows the correlations between the parameters pertaining to bone constituents and microstructure (the percentage of denatured collagen, weight fractions of mineral and organic phase, and porosity). Strong correlations were found between the percentage of denatured collagen and the weight fraction of mineral, porosity and mineral weight fraction, and weight fractions of the mineral and organic phase.

\section{DISCUSSION}

Bone is a natural composite material, primarily comprising mineral matrix reinforced by a collagenous network. From a materials science perspective, the mineral phase most likely imparts stiffness and strength to the bone, whereas the compliant collagen network functions as a reinforcement of the tissue to enhance its toughness. To test this hypothesis. cortical bone samples from baboon femurs were examined as a function of age, and the correlation of the integrity of collagen molecules with the biomechanical properties of bone was explored in this study. Age related changes of bone were manifested in the increased amount of denatured collagen, increased elastic modulus, and decreased fracture toughness and energy to fracture. With increasing age, no statistically significant changes were observed in the porosity, weight fractions of mineral and organic components. and strength of bone. Multiple regression analyses showed the amount of denatured collagen had a strong correlation with the toughness of bone, whereas the strength of bone primarily correlates with the mineral content in bone. These results indicate the mineral and
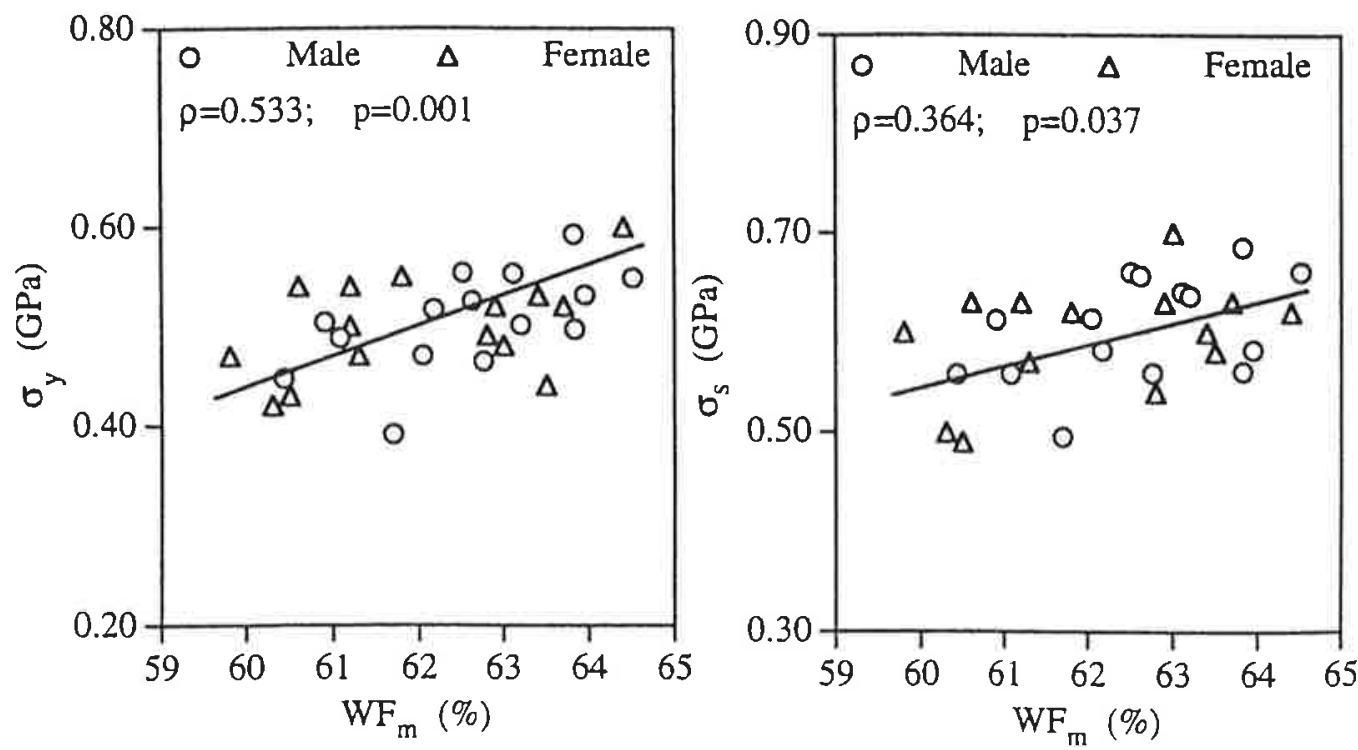

Fig 3. Regression of the yield strength $\left(\sigma_{y}\right)$ and ultimate strength $\left(\sigma_{s}\right)$ with respect to the mineral content $\left(W F_{m}\right)$ of bone for both genders, with the correlation coefficient $(\rho)$ and $p$ values being presented. Strong correlations were found between these parameters. 

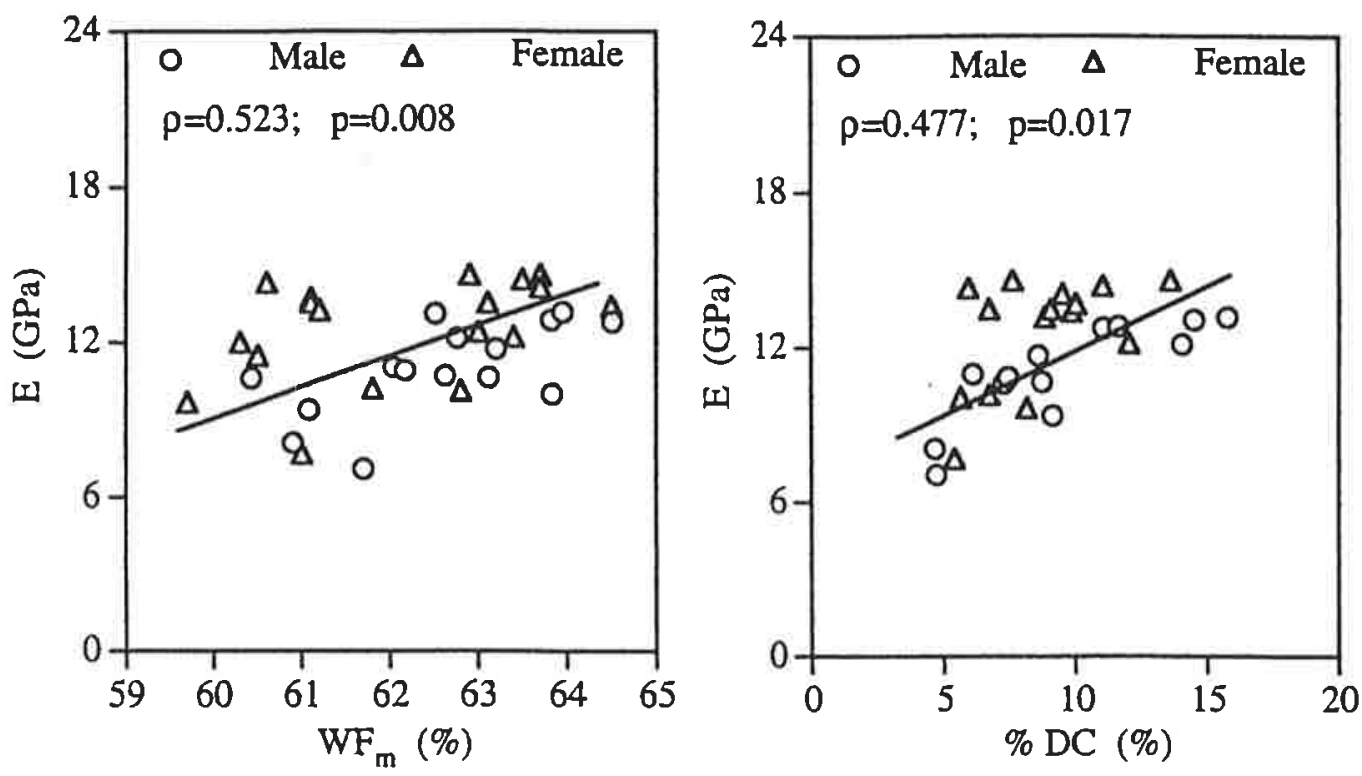

Fig 4. Regression of the stiffness $(E)$ with respect to the mineral content $\left(W F_{m}\right)$ and collagen denaturation (\%DC) of bone for both genders, with the correlation coefficient $(\rho)$ and $p$ values being presented. Strong correlations were found between these parameters.

collagen phases in bone play different roles in determining bone biomechanical properties.

In the current study, baboon bone samples had no statistically significant changes in porosity and strength with increasing age, unlike results obtained from human cortical bone. ${ }^{35.52 .53}$ This difference is most likely because of the differences between the two species. For instance, reported porosity values for human cortical bone vary between $5 \%$ and $30 \% .{ }^{35.53}$ whereas the porosity value for baboon bone in this study was less than $8 \%$, and the mean was less than $4.7 \%$. Given such small values and other potential nonage related differences between the specimens, it is likely tests in the current study were unable to detect age related changes in the porosity of baboon bone. In addition, considering that there was little variation in mineral content and porosity in the baboon bone specimens tested (Table 1), no significant changes in bone strength would be expected because bone strength primarily is determined by these factors. ${ }^{35.48}$ However, the intent in the current study was to investigate the correlation between collagen and the biomechanical properties of bone. Although age related changes in baboon bone may not closely mimic similar changes in human bone, it is unlikely this difference would significantly influence the correlation between bone properties. For instance, the correlations between the elastic modulus, ultimate strength, energy to fracture, and fracture toughness (Tables 2,3) observed in the current study also are reported for human bone, ${ }^{54}$ suggesting a similarity in bone properties between these two species.

Type I collagen fibers comprise $90 \%$ of the organic component of bone and usually are oriented in a preferential direction. ${ }^{7}$ Such a highly organized collagen network not only provides a framework for mineral to deposit, but also functions as a reinforcement of the composite. Thus, changes in the collagen network in bone potentially can lead to variation of bone mechanical properties. Changes in collagen network may occur at different levels: collagen denaturation is characterized by 


\section{TABLE 2. Correlation Coefficients for Bone Mechanical Properties}

\begin{tabular}{lrrlll}
\hline Parameters & $K_{1 C}$ & $W_{f}$ & $E$ & $\sigma_{y}$ & $\sigma_{s}$ \\
\hline$K_{1 C}$ & 1 & & & & \\
$W_{f}$ & $0.599^{*}$ & 1 & & & \\
$E$ & $-0.480^{*}$ & $-0.358^{*}$ & 1 & & \\
$\sigma_{Y}$ & 0.138 & 0.208 & $0.349^{*}$ & 1 & 1 \\
$\sigma_{S}$ & 0.283 & $0.538^{*}$ & 0.218 & $0.746^{*}$ & 1 \\
\hline
\end{tabular}

$K_{1 C}=$ Iracture toughness; $W_{1}=$ energy to fracture; $E=$ elastic modulus; $\sigma_{y}=$ yield strength; $\sigma_{s}=$ ultimate strength

-Significant correlation.

unwinding and cleavage of triple helical molecules. ${ }^{6}$ Intermolecular collagen crosslinks play an important role in retaining the structural stability of the collagenous network. ${ }^{41}$ Morphologically, changes in the orientation, spatial arrangement, and geometry of collagen fibrils may affect bone biomechanical properties. ${ }^{33,34}$

In the past, studies have investigated the correlation of crosslinks concentration and orientation of collagen network with bone biomechanical properties. In testing femurs from copper deficient rats. Jonas et $\mathrm{al}^{24}$ reported that reduction of crosslinks induced by copper deficiency leads to significant decreases in bone stiffness, strength, and its capacity to absorb energy to fracture. In another study, Lees et $\mathrm{a}^{31}$ found that rats treated by $\alpha$-amino-propionitrile have a reduced concentration of collagen crosslinks in bone, and this reduction is associated with a decrease in bone structural strength. In addition, collagen orientation has been found to have an effect on bone mechanical properties. In equine cannon bone, Martinet $\mathrm{al}^{34}$ observed that longitudinal collagen fiber orientation is regionally variable and contributes to increased modulus and strength but not to the fatigue life of bone.

The results of the current study show that denaturation of collagen had strong correlations with the fracture toughness, energy to fracture, and elastic modulus of bone. Normal collagen molecules have a triple helical structure, whereas the denatured collagen is characterized by unfolding and cleavage of the triple helixes. When these molecules some- how are unwound or cleaved, they are mechanically less stable and potentially lose their strength. Because collagen molecules are the building unit of the collagen network and may play a role in sustaining the toughness of bone, such adverse changes would weaken the collagen network and consequently lead to increased propensity of bone to fracture. The underlying mechanisms of age related collagen denaturation remain unclear but most likely involve an accumulation of damaged collagen molecules with increasing age, either because of the fatigue of the network or as a consequence of collagenolytic enzyme activities.

The contribution of mineral phase to bone biomechanical properties has been investi-

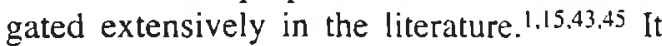
has been reported that the elastic modulus of bone increases with increasing mineral content. ${ }^{12} \cdot 16,17.20 .45$ Other studies have shown bone strength is determined by bone mineral density. ${ }^{9,15,36,47}$ Bone mineral density measured using quantitative computed tomogra-

TABLE 3. Correlation Coefficients for Bone Physical Properties

\begin{tabular}{lcccc}
\hline Parameters & $\% D C$ & $W_{m}$ & $W_{F_{o}}$ & Po \\
\hline$\% D C$ & 1 & & & \\
$W F_{m}$ & $0.545^{\circ}$ & 1 & & \\
$W F_{o}$ & -0.033 & $-0.432^{*}$ & 1 & \\
Po & -0.133 & $-0.382^{*}$ & 0.032 & 1 \\
\hline
\end{tabular}

$\% D C=$ percentage of denatured collagen; $W F_{m}=$ minera weight fraction; $W F_{0}=$ organic weight fraction; $P O=$ porosity. -Significant correlation. 
phy or other densitometries is a measure of mineral content in a unit volume of bone, which is not a true mineral density, but an apparent bone mineral density. Thus, its value can be influenced by two factors: porosity and true mineral density (or mineral content) so changes in porosity or mineral content may cause changes in bone strength. ${ }^{35} \mathrm{~A}$ similar trend was observed in the current study, showing an increase in the strength and elastic modulus of bone as mineral content increases.

Apparent mineral density or bone density have been shown to have a significant correlation with the toughness of bone in terms of fracture toughness or energy to fracture. ${ }^{52.54}$ However, no significant correlation has been reported between true mineral content and the fracture toughness of bone. ${ }^{50.52} \mathrm{~A}$ similar result was obtained for baboon bone in the current study, indicating mineral content may not play a significant role in the toughness of bone.

The data of this study showed that collagen denaturation also has a strong correlation with the elastic modulus of bone, suggesting that the modulus increases with collagen denaturation. Because collagen is more compliant than bone mineral (hydroxyapatite), according to the laws of mixtures for composite materials, ${ }^{27.30}$ it should not play a major role in determining bone stiffness. Thus, it is unlikely changes in the collagen phase have a direct effect on the stiffness of bone. However, it is possible denaturation of collagen molecules may affect subsequent mineralization and consequently lead to changes in the stiffness. The results of the current study indicate a remarkable interaction between the mineral content and collagen denaturation, showing that the mineral content of bone positively correlates with collagen denaturation (Table 3 ). Abnormal collagen molecules have significant effects on the mineralization of bone. For example, osteogenesis imperfecta, also known as brittle bone disease, has been found to involve an abnormality in the synthesis or structure of Type I collagen in bone, which subsequently leads to abnormal mineralization and increased susceptibility of bone to fracture. ${ }^{13}$
The results of the carrent study indicate the toughness of bone significantly decreases with increasing age in the baboon model. Such increased susceptibility to fracture most likely results from age dependent changes in bone constituents. The mineral content of bone appears to contribute to the strength and elastic modulus of bone. In addition, collagen denaturation shows a significant correlation with bone mineral content and elastic modulus. In the current study, a strong correlation found between the amount of denatured collagen molecules and the toughness of bone suggests changes in collagen molecules can significantly alter the fragility of bone. However, the underlying mechanism remains unclear, additional investigations are needed. A better understanding of this issue potentially can lead to collagen targeted therapies to reduce the risk of fracture in the elderly.

\section{Acknowledgments}

The authors thank C.H. Yuan, PhD, for his advice and assistance in the statistical analysis of experimental data, and S. McAnn and M. Silva for their assistance in preparing the baboon tissue.

\section{References}

I. Alho A. Husby T, Høiseth A, Fønselien E: Bone mineral content and mechanical strength of human femur. Fin J Orthop Trauma 8:56-57. 1985.

2. Aspray TJ, Prentice A, Cole TJ, et al: Low bone mineral content is common but osteoporotic fractures are rare in elderly rural Gambian women. J Bone Miner Res 11:1019-1025. 1996.

3. ASTM Standard: D790-86: Standard Test Methods for Flexural Properties of Unreinforced and Reinforced Plastics and Electrical Insulating Materials. Philadelphia. American Society for Testing and Ma terials 1986.

4. ASTM Standard: E 399-90: Standard Test Method for Plane Strain Fracture Toughness of Metallic Ma terials. Philadelphia. American Society for Testing and Materials 1993

5. Aufdemorte TB, Fox WC, Miller D, et al: A non-human primate model for the study of osteoporosis and oral bone loss. Bone 14:581-586, 1993

6. Bank RA, Krikken M, Beekman B. et al: A simplified measurement of degraded collagen in tissues: Application in healthy, fibrillated and osteoarthritic cartilage. Matrix Biol 16:231-241, 1997.

7. Baron R: Anatomy and Ultrastructure of Bone. In Favus MJ (ed). Primer on the Metabolic Bone Diseases and Disorders of Mineral Metabolism. New York. Lippincott-Raven 3-9, 1993. 
8. Bätge $B$, Winter $C$, Notbohm $\mathrm{H}$, et al: Glycosylation of human bone collagen $I$ in relation to lysylhydroxylation and fibril diameter. I Biochem 122:109-115, 1997.

9. Beck TJ, Christopher BR, Warden KE, Scolt WW: Predicting femoral neck strength from bone mineral data: A structural approach. Invest Radiol 25:6-18, 1990.

10. Boyce TM, Bloebaum RD: Cortical aging differences and fracture implications for the human femoral neck. Bone 14:769-778, 1993.

11. Burstein AH, Reilly DT, Martens M: Aging of bone tissue: Mechanical properties. J Bone Joint Surg 58A:82-86, 1976.

12. Burstein AH, Zika JM, Heiple KG, Klein L: Contribution of collagen and mineral to the elastic-plastic properties of bone. J Bone Joint Surg 57A:956-961, 1975.

13. Cassella JP, Ali SY: Abnormal collagen and mineral formation in osteogenesis imperfecta. Bone Miner 17:123-128, 1992.

14. Cummings SR, Black DM, Nevitt MC, et al: Appendicular bone density and age predict hip fracture in women. JAMA 263:665-668, 1990.

15. Currey JD: The mechanical consequences of variation in the mineral content of bone. J Biomech 2:477-480, 1969.

16. Currey JD: The effects of strain rate, reconstruction, and mineral content on some mechanical properties of bovine bone. J Biomech 8:81-86, 1975

17. Currey JD: The effect of porosity and mineral content on the Young's modulus of elasticity of compact bone. J Biomech 21:131-139, 1988.

18. Danielsen CC: Age-related thermal stability and susceptibility to proteolysis of rat bone collagen. Bio chem 272:697-701, 1990.

19. Danielsen CC, Andreassen TT, Mosekilde L: Mechanical properties of collagen from decalcified rat femur in relation to age and in vitro maturation. Calcif Tissue Int 39:69-73, 1986.

20. Hasegawa K, Tumer CH, Burt DB: Contribution of collagen and mineral to the elastic anisotropy of bone. Calcif Tissue Int 55:381-386, 1994.

21. Hui SL, Slemenda CW, Johnson CC: Age and bone mass as predictors of fracture in a prospective study $\mathrm{J}$ Clin Invest 81:1804-1809, 1988

22. Jepsen KJ, Goldstein SA, Kuhn JL, Schaffler MB, Bonadio J: Type-I collagen mutation compromizes the post-yield behavior of Mov 13 long bone. J Orthop Res 14:493-499, 1996.

23. Jepsen KJ, Schaffler MB, Kuhn JL, et al: Type I collagen mutation alters the strength and fatigue behavior of Mov13 cortical tissue. J Biomech 30:11411147,1997

24. Jonas J, Bums J Abel EW, et al: Impaired mechanical strength of bone in experimental copper deficiency. Ann Nutr Metab 37:245-252, 1993.

25. Jonas J, Bums J Abel EW et al: A technique for the tensile testing of demineralized bone. J Biomech 26:271-276, 1993

26. Kannus $P$, Parkkari J, Sievänen $H$, et al: Epidemiology of hip fractures. Bone 18(Suppl 1):57S-63S 1996.

27. Katz JL: Anisotropy of Young's modulus of bone. Nature 283:106-107, 1980.
28. Kovach IS, Agrawal CM, Richards-Kortum $R$ Wang $\mathrm{X}$, Athanasiou KA: Laser-induced autofluorescence and fracture toughness of baboon cortical bone. Trans Orthop Res Soc 22:37, 1997.

29. Kovach IS, Wang X, Agrawal CM, Richards-Kortum AR, Athanasiou KA: A novel optical technique to characterize intact cortical bone. Toronto, 5th World Biomaterials Congress 19, 1996

30. Lees S, Davidson CL: The role of collagen in the elastic properties of calcified tissues. J Biomech $10: 473-486,1977$

31. Lees S, Hanson D, Page E, Mook HA: Comparison of dosage-dependent effects of b-aminopropionitrile, sodium floride, and hydrocortisone on selected physical properties of cortical bone. J Bone Miner Res 9:1377-1389, 1994.

32. Lotz JC: Hip Fracture Risk Predictions by X-ray Computed Tomography. PhD Dissertation. Cambridge, Massachusetts Institute of Technology 1988.

33. Martin RB, Boardman DL: The effects of collagen fiber orientation, porosity, density, and mineralization on bovine cortical bone bending properties. J Biomech 26:1047-1054, 1993.

34. Martin RB, Lau ST. Mathews PV, Gibson VA. Stover SM: Collagen fiber organization is related to mechanical properties and remodeling in equine bone. A comparison of two methods. I Biomech 29:1515-1521. 1996

35. McCalden RW, McGeough JA. Barker MB. CourtBrown CM: Age-related changes in the tensile properties of cortical bone. J Bone Joint Surg 75A:1193-1205, 1993

36. Mosekilde L: Normal aged-related changes in bone mass, structure and strength-consequences of the remodeling process. Dan Med Bull 40:65-83, 1993.

37. Mundy GR: Anatomy, Physiology. and Function of Bone. Kalamazoo, MI, The Upjohn Company 4042,1989

38. Norman TL, Nivargikar SV, Burr DB: Resistance to crack growth in human cortical bone is greater in shear than in tension. J Biomech 29:1023-1031, 1996.

39. Notbohm H. Mosler S, Bodo M, et al: Compurative study on the thermostability of collagen I of skin and bone: Influence of posttranslational hydroxylation of prolyl and lysyl residues. J Protein Chem 11:635643. 1992.

40. Ott SM: When bone mass fails to predict bone fai\}ure. Calcif Tissue Int 53(Suppl 1):S7-S 13, 1993

41. Oxlund H, Barckman M, Ørtoft G. Andreassen TT: Reduced concentration of collagen cross-links are associated with reduced strength of bone. Bone 17 (Suppl):365S-371S, 1995.

42. Oxlund H. Mosekilde L. Ørtoft G: Reduced concentration of collagen reducible cross links in human trabecular bone with respect to age and osteoporosis. Bone 19:479-484, 1996.

43. Parfitt AM: Bone age, mineral density, and fatigue damage. Calcif Tissue Int 53(Suppl 1):S82-S86. 1993

44. Reinbold WD Genant HK, Reiser UJ, Harris ST Ettinger B: Bone mineral content in early-postmenopausal osteoporotic women and postmenopausal women: Comparison of measurement methods. Radiology 160:469-478, 1986. 
45. Sasaki N, Matsushima N, Ikawa T, Yamamura $H$, Fukuda A: Orientation of bone mineral and its role in the anisotropic mechanical properties of bone-transverse anisotropy. J Biomech 22:157-164, 1989.

46. Schaffler MB, Burr DB: Stiffness of compact bone Effects of porosity and density. J Biomech $21: 13-16$, 1988.

47. Seeley DG, Browner WS, Cummings SR, Genant HK: Which fractures are predicted with measurement of bone mineral density? Radiology 177(P):128, 1990.

48. Smith CB, Smith DA: Relations between age, mineral density and mechanical properties of human femoral compacta. Acta Orthop Scand 47:496-502, 1976.

49. Termine JD: Bone Matrix Proteins and the Mineralization Process. In Favus MJ (ed). Primer on the Metabolic Bone Diseases and Disorders of Mineral Metabolism. New York, Lippincott-Raven 21-25, 1993.
50. Wang X, Masilamani NS, Mabrey JD, Alder ME, Agrawal CM: Changes in the fracture toughness of bone may not be reflected in its mineral density, porosity, and tensile properties. Bone 23:67-72, 1998.

51. Weiner S, Arad T, Sabanay I, Traub W: Rotated plywood structure of primary lamellar bone in the rat: Orientation of the collagen fibril arrays. Bone 20:509-514, 1997.

52. Yeni YN, Brown CU, Noman TL: The influence of bone composition and apparent density on fracture toughness of human femur and tibia. Bone 22:79-84, 1998.

53. Yeni YN, Brown CU, Wang Z, Norman TL: The influence of bone morphology on fracture toughness of the human femur and tibia. Bone 21:453-459, 1997.

54. Zioupos P, Currey JD: Changes in the stiffness, strength, and toughness of human cortical bone with age. Bone 22:57-66, 1998. 